\title{
Categorisation of Pharmaceutical Adverse Events Using the Japanese Adverse Drug Event Report Database: Characteristic Adverse Drug Events of the Elderly Treated with Polypharmacy
}

\author{
Akio Negishi ${ }^{1} \cdot$ Shinji Oshima ${ }^{1}$ (D) $\cdot$ Norimitsu Horii ${ }^{2,3} \cdot$ Mizue Mutoh $^{2} \cdot$ Naoko Inoue $^{2,3} \cdot$ Sachihiko Numajiri $^{4}$. \\ Shigeru Ohshima ${ }^{2,3} \cdot$ Daisuke Kobayashi ${ }^{1,3}$
}

Accepted: 20 November 2020 / Published online: 23 December 2020

(c) The Author(s) 2020

\begin{abstract}
Background Pharmacokinetics and pharmacodynamics of drugs in elderly individuals differ from those in younger adults; thus, adverse drug events (ADEs) are common in older patients with polypharmacy because co-existing comorbidities elevate the risk of ADEs occurring. However, ADEs have not yet been characterised based on the elderly patients of Japanese origin and polypharmacy.

Objective The 100 most commonly reported ADEs were grouped into four classes (Class 1-Class 4) based on elderly patients with polypharmacy.

Patients and Methods In this study, logistic regression analysis was performed using cases recorded in the Japanese Adverse Drug Event Report (JADER) database.

Results ADEs in elderly patients treated with polypharmacy —in whom the risk of electrolyte abnormalities, renal and respiratory disorders, and coagulopathy was high-were categorised as 'Class $1[\mathrm{E}(+), \mathrm{P}(+)]$ ', while ADEs in elderly patients not treated with polypharmacy-in whom the risk of delirium and fall was high-were categorised as 'Class $2[\mathrm{E}(+)$, $\mathrm{P}(-)]$ '. When there was no association with being elderly, ADEs associated with polypharmacy that carried a high risk of myelosuppression and infection were categorised as 'Class $3[\mathrm{E}(-), \mathrm{P}(+)]$ ', and allergic ADEs that were not affected by being elderly or polypharmacy, were categorised as 'Class $4[\mathrm{E}(-), \mathrm{P}(-)]$ '. Class 1 events as well as Class 3 ADEs occurred more frequently in females than in males, whereas Class 3 ADEs (deep vein thrombosis and pulmonary embolism) occurred more frequently in males.
\end{abstract}

Conclusions Class 1 and Class 2 ADEs should be investigated in analyses that focus on individual drugs.

Supplementary Information The online version contains supplementary material available at https://doi.org/10.1007/s4080 1-020-00221-8.

Shinji Oshima

soshima@josai.ac.jp

1 Laboratory of Analytical Pharmaceutics and Informatics, Faculty of Pharmacy and Pharmaceutical Sciences, Josai University, 1-1 Keyakidai, Sakado, Saitama 350-0295, Japan

2 Laboratory of Pharmacy Management, Faculty of Pharmacy and Pharmaceutical Sciences, Josai University, Saitama, Japan

3 Josai University Pharmacy, Saitama, Japan

4 Student Learning Assistance Centre, Faculty of Pharmacy and Pharmaceutical Sciences, Josai University, Saitama, Japan

\section{Key Points}

Using the Japanese Adverse Drug Event Report database, adverse drug events were categorized into four classes (Class 1-Class 4) based on age (elderly $\longrightarrow \geq 70$ years) and polypharmacy (six or more agents).

Among the adverse drug events associated with elderly patients, the risks of electrolyte abnormality, renal disorder, respiratory disorder, and coagulopathy were associated with polypharmacy (Class 1).

Among the adverse drug events associated with elderly patients, the risks of delirium and fall were not associated with polypharmacy (Class 2). 


\section{Introduction}

As a result of changes in physiological function that occur with aging, pharmacokinetics and organic drug responses (i.e. pharmacodynamics) differ between the elderly and the non-elderly [1-5]. Because of this, the risk of adverse drug events (ADEs) is higher in the elderly than in the non-elderly [1-6]. Since co-existing comorbidities tend to increase in frequency with age, there is a tendency for polypharmacy prescribing for the elderly [2, 3, 7, 8]. Polypharmacy, the simultaneous use of multiple medications by patients, has been linked to reduced adherence to medication, prolongation of hospitalisation, readmission to hospital immediately after discharge, mortality, ADE incidence, and elevated risks of drug interaction [3, 4]. Moreover, follow-up prescriptions ('prescription cascades') of concomitant drugs for occurring ADEs also give rise to polypharmacy [4]. This type of polypharmacy treatment in the elderly, which is linked to adverse outcomes, has been reported as a global public health issue [9]. ADEs induced by polypharmacy increase dramatically in patients prescribed five to six drugs [2].

In this way, aging and polypharmacy increase the risk of ADEs. It is said that the geriatric syndromes (such as delirium, falling, dizziness, and urinary incontinence) are non-specific and do not fit into a single deficit diagnosis [10]. In other words, it can be considered that the risk of certain ADEs in elderly patients receiving polypharmacy increases not because of specific drugs but because of an increase in the number of drugs administered. Therefore, we hypothesized that the elderly may be vulnerable to certain ADEs, given that they have higher sensitivity to drugs. Thus, the identification of which ADEs are likely to be caused by aging and polypharmacy would make it easier to observe these ADEs more closely for managing drug treatment effectively in the elderly.

Focusing on cases recorded in the Japanese Adverse Drug Event Report (JADER) database from the perspectives of polypharmacy and aging, we grouped the 100 most commonly reported ADEs into four classes (Class 1-Class 4) and investigated the influence of these two factors on the risk of ADEs.

\section{Methods}

\subsection{Database Information}

The JADER was downloaded from the Pharmaceuticals and Medical Devices Agency website (http://www.info. pmda.go.jp/fukusayoudb/CsvDownload.jsp). JADER is the database of collected and published cases of ADEs that were reported by pharmaceutical companies and medical staff, and is used for pharmacovigilance activities. All cases recorded from April 2004 to July 2018 were used. The JADER is composed of four tables: a 'demo' table, a 'drug' table, a 'reac' table, and a 'hist' table, across which each case is linked by the assignment of a common identification number. Data on patients such as age and sex are presented in the 'demo' table, data on drugs used in cases are presented in the 'drug' table, data on ADEs that have occurred in cases are presented in the 'reac' table, and primary disease data are presented in the 'hist' table. For this study, we used the 'demo', 'drug' and 'reac' tables. The 'drug involvement' from the drug table in JADER mentions 'Suspected drug', 'Co-administered drug' or 'Interactions' for each drug. However, this study did not use the 'drug involvement' information as the study did not focus on individual drugs. The study instead examined all the registered drugs. The ADEs used in this study were entered in the database using the preferred terms (PTs) from the Medical Dictionary for Regulatory Activities/J (MedDRA/J), version 21.0. All processing was performed at the PT level.

\subsection{Adverse Drug Events (ADEs)}

All ADEs recorded in JADER were extracted from the reac table, and the total number of reports was calculated for each. We then ranked the top 100 ADE cases according to their frequency based on the information that we referred to. This study analysed these 100 ADEs. Cases in which none of the 100 ADEs were observed were also included as a control group.

\subsection{Data Cleaning}

The data-cleaning procedure is shown in Fig. 1. First, cases clearly denoted by 'sex' and 'age' were extracted from the JADER demo table. Then, we used the reac table to prepare combinations of identification number-ADEs-date of ADEs,' applying each combination to a single case. ADEs reported with the same identification number were counted as different cases. Then, using the common identification number for each case, we extracted 'sex' and 'age' from the demo table, 'drug name (generic name),' 'date of start of use' and 'date of termination of use' from the drug table, and 'ADEs' and 'date of ADEs occurrence' from the reac table. Year, month and day were used to denote the start of drug use and the termination of drug use, and for the date of ADE occurrence. By excluding drugs that were administered before or after the ADE occurrence, the remaining drugs were considered to have been used at the time of occurrence. Drugs with no clear record of the start or termination dates 


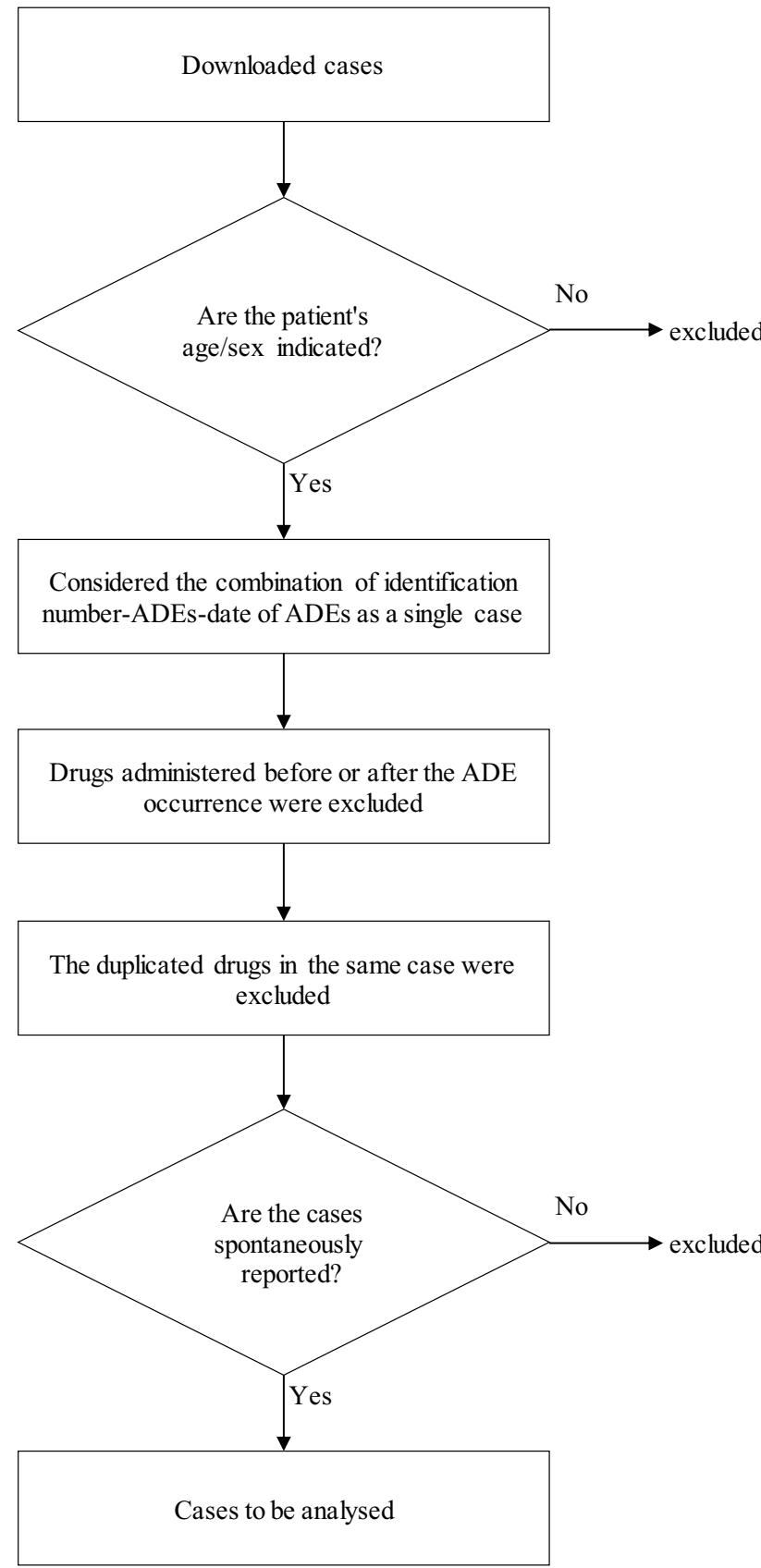

Fig. 1 Data-cleaning procedure. $A D E$ adverse drug event

of use and those that were used at the time of ADE occurrence were regarded as patient-use drugs. When different dosages of the same drug were included in multiple records for a single case, the drug was counted as a single agent. The JADER also includes clinical trial data, thus spontaneously reported cases were included in the analysis, while clinical trial data were excluded.

\subsection{Data Analysis}

Cases were divided into men and women, and subsequent analyses were conducted separately for each sex. We counted the number of concomitant drugs for each case. Based on previous studies, polypharmacy was defined as cases where the patient was treated with six or more concomitant drugs and non-polypharmacy cases where the patient was treated with less than six drugs $[11,12]$. Although 'elderly' generally refers to individuals aged 65 years and older, as age is grouped by decade in the JADER, 'elderly' was defined as patients aged 70 years or more and 'non-elderly' was defined as those aged less than 70 years [13].

In this study, we used logistic regression analysis to analyse the factors 'elderly' and 'polypharmacy', because it can be used to simultaneously analyse multiple factors [14]. Next, to investigate the influence of elderly and polypharmacy, with $x_{e}$ as the presence or absence of elderly, and $x_{p}$ as the presence or absence of polypharmacy with respect to the reporting rate for each ADE in the JADER database, $p$, we performed logistic regression analysis according to Eq. 1:

$\ln \frac{p_{i}}{1-p_{i}}=a_{\mathrm{e}_{i}} \times x_{\mathrm{e}_{i}}+a_{\mathrm{p}_{i}} \times x_{\mathrm{p}_{i}}+b_{0_{i}}$.

The natural exponential function of the partial regression coefficient $\left(a_{\mathrm{e}}\right.$ or $a_{\mathrm{p}}$ ) derived from logistic regression analysis with Eqs. (2) and (3) being the adjusted odds ratio (adjusted $\mathrm{OR})$, elderly risk $\left(\mathrm{OR}_{\mathrm{e}}\right)$ and polypharmacy risk $\left(\mathrm{OR}_{\mathrm{p}}\right)$ were calculated for each ADE. Non-association between 'elderly' or 'polypharmacy' and ADE onset is represented by OR 1 , while it is represented by OR $>1$ where there is risk of ADE onset. In this study, a significant risk was defined as a $95 \%$ confidence interval of OR.

$\mathrm{OR}_{\mathrm{e}_{i}}=e^{a_{e_{i}}}$

$\mathrm{OR}_{\mathrm{p}_{i}}=e^{a_{\mathrm{p}_{i}}}$

\subsection{ADE Categorisation}

Using $\mathrm{OR}_{\mathrm{e}}$ and $\mathrm{OR}_{\mathrm{p}}$ derived from logistic regression analysis, 100 types of ADEs were grouped into four classes (Fig. 2). First, ADEs for which $\mathrm{OR}_{\mathrm{e}}$ significantly exceeded 1 were grouped into Classes 1 and 2, and all other ADEs were grouped into Classes 3 and 4. Next, of the ADEs categorised as Class 1 and Class 2, those in which $\mathrm{OR}_{\mathrm{p}}$ significantly exceeded 1 were grouped into Class $1[\mathrm{E}(+), \mathrm{P}(+)]$ and the remainder into Class $2[\mathrm{E}(+), \mathrm{P}(-)]$. Again, of the ADEs categorised as Class 3 and Class 4, those in which $\mathrm{OR}_{\mathrm{p}}$ significantly exceeded 1 were grouped into Class $3[\mathrm{E}(-), \mathrm{P}(+)]$ and the remainder into Class $4[\mathrm{E}(-), \mathrm{P}(-)]$. 
Fig. 2 Categorisation of adverse drug events (ADEs) considering elderly and polypharmacy. $O R_{e}$ adjusted odds ratio with elderly as a factor for the occurrence of ADEs, $O R_{p}$ adjusted odds ratio with polypharmacy as a factor for the occurrence of ADEs. $\mathrm{E}(+), \mathrm{P}(+)$ : ADEs where $\mathrm{OR}_{\mathrm{e}}$ and $\mathrm{OR}_{\mathrm{p}}$ significantly exceeded $1 ; \mathrm{E}(+), \mathrm{P}(-)$ : ADEs where only $\mathrm{OR}_{\mathrm{e}}$ significantly exceeded $1 ; \mathrm{E}(-), \mathrm{P}(+)$ : ADEs where only $\mathrm{OR}_{\mathrm{p}}$ significantly exceeded $1 ; \mathrm{E}(-), \mathrm{P}(-)$ : ADEs where neither $\mathrm{OR}_{\mathrm{e}}$ nor $\mathrm{OR}_{\mathrm{p}}$ significantly exceeded 1

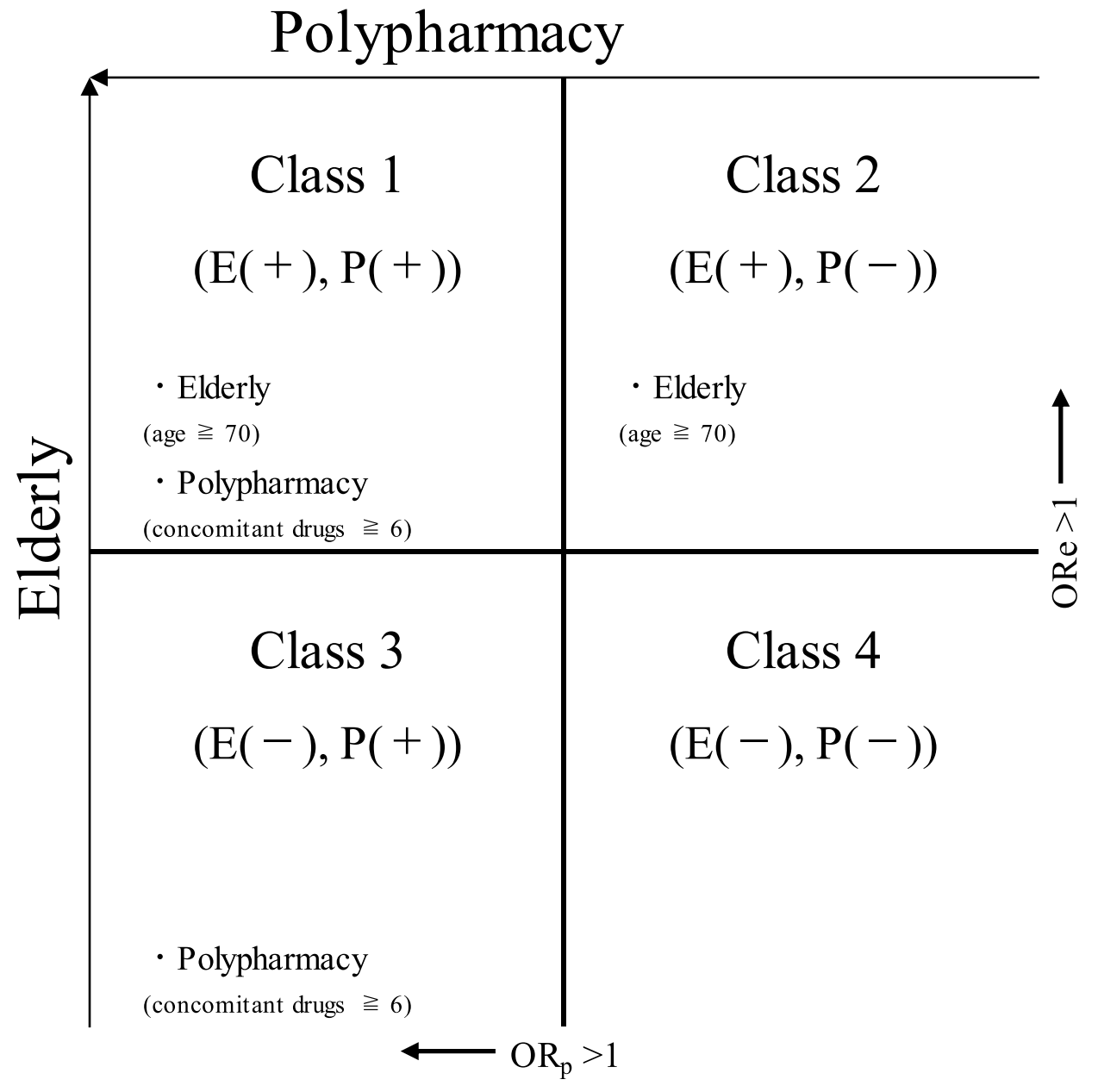

\section{Results}

\subsection{ADEs in Identified Cases}

Total cases registered in JADER (combinations of identification number-ADE-date of ADE) comprised 355,855 men and 349,460 women. The average number of drugs that the patients used simultaneously was $4.25 \pm 4.56$, and the median age of the study group was 70 years. The 100 most common types of ADEs are collated by report number in Table 1; these were subsequently targeted for analysis.

\subsection{ADEs That are Associated with Both Elderly and Polypharmacy: Class $1[\mathrm{E}(+), \mathrm{P}(+)]$}

ADEs categorised as Class 1 are presented by sex in Table 2 ((a) Males, (b) Females). The ADEs in Table 2 were ranked in descending order of $\mathrm{OR}_{\mathrm{e}}$ and $\mathrm{OR}_{\mathrm{p}}$ volume. A total of 19 and 26 male and female ADE types, respectively, were categorised as Class 1. Of these, 16 ADE types were categorised as common to both males and females.
$\mathrm{OR}_{\mathrm{e}}$ for males included hypoglycaemia (OR 2.03), bradycardia (OR 2.03), hyperkalaemia (OR 1.76), interstitial lung disease (OR 1.74), and hyponatraemia (OR 1.73). For females, ADEs included hyperkalaemia (OR 3.68), hypoglycaemia (OR 3.42), hyponatraemia (OR 3.18), bradycardia (OR 2.82), and renal failure (OR 2.49).

$\mathrm{OR}_{\mathrm{p}}$ for males included hyperkalaemia (OR 1.89), transfusion-related acute lung injury (OR 1.71), dehydration (OR, 1.71), bradycardia (OR 1.49), and respiratory failure (OR 1.43). For females, the ADEs included disseminated drug interaction (OR 2.26), hyperkalaemia (OR 1.90), transfusion-related acute lung injury (OR 1.89), hypokalaemia (OR 1.66), and rhabdomyolysis (OR 1.65).

Many of the ADEs categorised as Class 1 were related to electrolyte abnormalities, renal and respiratory disorders, and coagulopathy. Comparison of male and female ADEs identified as Class 1 revealed that lung disorders, increased blood creatinine, and dizziness were significant for males only, and that ten ADE types (drug interaction, urinary retention, pneumonia aspiration, renal disorder, renal impairment, electrocardiogram QT prolonged, decreased 
Table 1 Top 100 adverse drug event (ADE) types considered for analysis

\begin{tabular}{|c|c|c|c|}
\hline No. & ADEs & No. & ADEs \\
\hline 1 & Interstitial lung disease & 51 & Stomatitis \\
\hline 2 & Platelet count decreased & 52 & Pneumocystis jirovecii pneumonia \\
\hline 3 & Hepatic function abnormal & 53 & Alanine aminotransferase increased \\
\hline 4 & Anaphylactic shock & 54 & Urticaria \\
\hline 5 & Neutrophil count decreased & 55 & Hyponatraemia \\
\hline 6 & White blood cell count decreased & 56 & Blood creatine phosphokinase increased \\
\hline 7 & Pyrexia & 57 & Dizziness \\
\hline 8 & Anaemia & 58 & Aspartate aminotransferase increased \\
\hline 9 & Pneumonia & 59 & Hyperkalaemia \\
\hline 10 & Liver disorder & 60 & Renal disorder \\
\hline 11 & Neutropenia & 61 & Hypertension \\
\hline 12 & Drug eruption & 62 & Bradycardia \\
\hline 13 & Diarrhoea & 63 & Hypokalaemia \\
\hline 14 & Renal impairment & 64 & Anaphylactoid reaction \\
\hline 15 & Blood pressure decreased & 65 & Rash generalised \\
\hline 16 & Decreased appetite & 66 & Delirium \\
\hline 17 & Febrile neutropenia & 67 & Erythema \\
\hline 18 & Rash & 68 & Renal failure \\
\hline 19 & Acute kidney injury & 69 & Pleural effusion \\
\hline 20 & Rhabdomyolysis & 70 & Depressed level of consciousness \\
\hline 21 & Thrombocytopenia & 71 & Urinary retention \\
\hline 22 & Pancytopenia & 72 & Diabetes mellitus \\
\hline 23 & Hypoglycaemia & 73 & Electrocardiogram QT prolonged \\
\hline 24 & Cerebral infarction & 74 & Deep vein thrombosis \\
\hline 25 & Nausea & 75 & Pulmonary embolism \\
\hline 26 & Erythema multiforme & 76 & Dehydration \\
\hline 27 & Anaphylactic reaction & 77 & Melaena \\
\hline 28 & Cardiac failure & 78 & Fall \\
\hline 29 & Stevens-Johnson syndrome & 79 & Drug interaction \\
\hline 30 & Haemoglobin decreased & 80 & Jaundice \\
\hline 31 & Altered state of consciousness & 81 & Herpes zoster \\
\hline 32 & Vomiting & 82 & Blood creatinine increased \\
\hline 33 & Shock & 83 & Lymphoproliferative disorder \\
\hline 34 & Seizure & 84 & Palmar-plantar erythrodysaesthesia syndrome \\
\hline 35 & Leukopenia & 85 & Headache \\
\hline 36 & Sepsis & 86 & Transfusion-related acute lung injury \\
\hline 37 & Cerebral haemorrhage & 87 & Cytomegalovirus infection \\
\hline 38 & Dyspnoea & 88 & Pancreatitis acute \\
\hline 39 & Loss of consciousness & 89 & Lung disorder \\
\hline 40 & Drug-induced liver injury & 90 & Respiratory failure \\
\hline 41 & $\begin{array}{l}\text { Drug reaction with eosinophilia and } \\
\text { systemic symptoms }\end{array}$ & 91 & Hyperglycaemia \\
\hline 42 & Malaise & 92 & Infection \\
\hline 43 & Bone marrow failure & 93 & Ileus \\
\hline 44 & Agranulocytosis & 94 & Pneumonia aspiration \\
\hline 45 & Disseminated intravascular coagulation & 95 & Toxicity to various agents \\
\hline 46 & Gastrointestinal haemorrhage & 96 & Septic shock \\
\hline 47 & Death & 97 & Tubulointerstitial nephritis \\
\hline 48 & Toxic epidermal necrolysis & 98 & Cellulitis \\
\hline 49 & Neuroleptic malignant syndrome & 99 & Toxic skin eruption \\
\hline 50 & Osteonecrosis of jaw & 100 & Peritonitis \\
\hline
\end{tabular}


Table 2 Adverse drug events (ADEs) categorised as Class $1\left(\mathrm{OR}_{\mathrm{e}}\right.$ and $\mathrm{OR}_{\mathrm{p}}$ volumes in descending order)

\begin{tabular}{|c|c|c|c|c|c|c|}
\hline \multicolumn{7}{|c|}{ (a) Male cases } \\
\hline No. & ADEs & $\mathrm{OR}_{\mathrm{e}}$ & $(95 \% \mathrm{CI})$ & $\mathrm{OR}_{\mathrm{p}}$ & $(95 \% \mathrm{CI})$ & Female class \\
\hline 1 & Hyperkalaemia & 1.76 & $(1.54-2.02)$ & 1.89 & $(1.65-2.16)$ & 1 \\
\hline 2 & Bradycardia & 2.03 & $(1.77-2.32)$ & 1.49 & $(1.30-1.70)$ & 1 \\
\hline 3 & Hypoglycaemia & 2.03 & $(1.86-2.22)$ & 1.29 & $(1.18-1.41)$ & 1 \\
\hline 4 & Transfusion-related acute lung injury & 1.43 & $(1.25-1.64)$ & 1.71 & $(1.49-1.97)$ & 1 \\
\hline 5 & Hyponatraemia & 1.73 & $(1.50-1.99)$ & 1.29 & $(1.11-1.49)$ & 1 \\
\hline 6 & Interstitial lung disease & 1.74 & $(1.67-1.82)$ & 1.17 & $(1.12-1.23)$ & 1 \\
\hline 7 & Dehydration & 1.18 & $(1.00-1.40)$ & 1.71 & $(1.44-2.02)$ & 1 \\
\hline 8 & Hypokalaemia & 1.48 & $(1.26-1.74)$ & 1.36 & $(1.15-1.60)$ & 1 \\
\hline 9 & Lung disorder & 1.48 & $(1.28-1.72)$ & 1.31 & $(1.12-1.53)$ & 2 \\
\hline 10 & Respiratory failure & 1.33 & $(1.14-1.56)$ & 1.43 & $(1.21-1.68)$ & 1 \\
\hline 11 & Renal failure & 1.41 & $(1.23-1.63)$ & 1.33 & $(1.15-1.55)$ & 1 \\
\hline 12 & Altered state of consciousness & 1.29 & $(1.17-1.42)$ & 1.41 & $(1.28-1.56)$ & 1 \\
\hline 13 & Anaemia & 1.45 & $(1.31-1.59)$ & 1.20 & $(1.08-1.33)$ & 1 \\
\hline 14 & Thrombocytopenia & 1.50 & $(1.35-1.66)$ & 1.13 & $(1.02-1.26)$ & 1 \\
\hline 15 & Blood creatinine increased & 1.36 & $(1.15-1.62)$ & 1.24 & $(1.03-1.49)$ & 2 \\
\hline 16 & Acute kidney injury & 1.20 & $(1.10-1.30)$ & 1.36 & $(1.25-1.47)$ & 1 \\
\hline 17 & $\underline{\text { Dizziness }}$ & 1.30 & $(1.12-1.50)$ & 1.22 & $(1.05-1.43)$ & 2 \\
\hline 18 & Pancytopenia & 1.24 & $(1.13-1.37)$ & 1.12 & $(1.00-1.24)$ & 1 \\
\hline 19 & Blood pressure decreased & 1.10 & $(1.02-1.18)$ & 1.16 & $(1.07-1.26)$ & 1 \\
\hline \multicolumn{7}{|c|}{ (b) Female cases } \\
\hline No. & ADEs & $\mathrm{OR}_{\mathrm{e}}$ & $(95 \% \mathrm{CI})$ & $\mathrm{OR}_{\mathrm{p}}$ & $(95 \% \mathrm{CI})$ & Male class \\
\hline 1 & Hyperkalaemia & 3.68 & $(3.12-4.37)$ & 1.90 & $(1.64-2.21)$ & 1 \\
\hline 2 & Hyponatraemia & 3.18 & $(2.79-3.64)$ & 1.65 & $(1.45-1.86)$ & 1 \\
\hline 3 & Hypoglycaemia & 3.42 & $(3.10-3.78)$ & 1.47 & $(1.34-1.61)$ & 1 \\
\hline 4 & Bradycardia & 2.82 & $(2.46-3.24)$ & 1.43 & $(1.25-1.64)$ & 1 \\
\hline 5 & Renal failure & 2.49 & $(2.08-2.98)$ & 1.61 & $(1.35-1.91)$ & 1 \\
\hline 6 & Dehydration & 2.48 & $(2.05-3.01)$ & 1.60 & $(1.32-1.93)$ & 1 \\
\hline 7 & Acute kidney injury & 2.35 & $(2.15-2.58)$ & 1.54 & $(1.41-1.69)$ & 1 \\
\hline 8 & Hypokalaemia & 2.16 & $(1.89-2.48)$ & 1.66 & $(1.45-1.90)$ & 1 \\
\hline 9 & Drug interaction & 1.43 & $(1.24-1.65)$ & 2.26 & $(1.96-2.61)$ & 3 \\
\hline 10 & Transfusion-related acute lung injury & 1.61 & $(1.38-1.88)$ & 1.89 & $(1.62-2.21)$ & 1 \\
\hline 11 & $\underline{\text { Urinary retention }}$ & 2.32 & $(1.96-2.76)$ & 1.26 & $(1.06-1.50)$ & 2 \\
\hline 12 & $\underline{\text { Pneumonia aspiration }}$ & 2.08 & $(1.66-2.61)$ & 1.38 & $(1.10-1.74)$ & 2 \\
\hline 13 & $\underline{\text { Renal disorder }}$ & 2.04 & $(1.74-2.39)$ & 1.25 & $(1.05-1.47)$ & 4 \\
\hline 14 & $\underline{\text { Renal impairment }}$ & 2.04 & $(1.86-2.23)$ & 1.21 & $(1.10-1.33)$ & 2 \\
\hline 15 & Electrocardiogram QT prolonged & 1.72 & $(1.48-1.99)$ & 1.42 & $(1.22-1.66)$ & 3 \\
\hline 16 & Altered state of consciousness & 1.71 & $(1.56-1.87)$ & 1.40 & $(1.27-1.53)$ & 1 \\
\hline 17 & Decreased appetite & 1.84 & $(1.65-2.06)$ & 1.21 & $(1.07-1.35)$ & 2 \\
\hline 18 & $\underline{\text { Rhabdomyolysis }}$ & 1.18 & $(1.07-1.30)$ & 1.65 & $(1.49-1.83)$ & 3 \\
\hline 19 & $\underline{\text { Cardiac failure }}$ & 1.70 & $(1.53-1.89)$ & 1.12 & $(1.00-1.25)$ & 2 \\
\hline 20 & Anaemia & 1.48 & $(1.34-1.62)$ & 1.29 & $(1.17-1.43)$ & 1 \\
\hline 21 & Pancytopenia & 1.58 & $(1.45-1.73)$ & 1.19 & $(1.08-1.31)$ & 1 \\
\hline 22 & Respiratory failure & 1.37 & $(1.14-1.64)$ & 1.31 & $(1.08-1.59)$ & 1 \\
\hline 23 & Blood pressure decreased & 1.28 & $(1.18-1.38)$ & 1.22 & $(1.12-1.33)$ & 1 \\
\hline 24 & Interstitial lung disease & 1.36 & $(1.29-1.43)$ & 1.10 & $(1.04-1.16)$ & 1 \\
\hline 25 & Thrombocytopenia & 1.13 & $(1.00-1.26)$ & 1.29 & $(1.14-1.45)$ & 1 \\
\hline 26 & Pneumonia & 1.30 & $(1.19-1.41)$ & 1.11 & $(1.01-1.22)$ & 2 \\
\hline
\end{tabular}

Underlined ADEs are categorised in a separate Class in the other sex

$O R_{e}$ adjusted odds ratio with elderly as a factor for the occurrence of ADEs, $O R_{p}$ adjusted odds ratio with polypharmacy as a factor for the occurrence of ADEs, 95\% CI 95\% confidence interval of $\mathrm{OR}_{\mathrm{e}}$ and $\mathrm{OR}_{\mathrm{p}}$, Female Class class in which ADEs common in females are categorised, Male Class class in which ADEs common in males are categorised 
Table 3 Adverse drug events (ADEs) categorised as Class 2 (in $\mathrm{OR}_{\mathrm{e}}$ descending order)

(a) Male cases

\begin{tabular}{|c|c|c|c|c|c|c|}
\hline No. & ADEs & $\mathrm{OR}_{\mathrm{e}}$ & $(95 \% \mathrm{CI})$ & $\mathrm{OR}_{\mathrm{p}}$ & $(95 \% \mathrm{CI})$ & Female class \\
\hline 1 & Urinary retention & 3.34 & $(2.93-3.82)$ & 0.79 & $(0.69-0.91)$ & 1 \\
\hline 2 & Fall & 2.29 & $(1.93-2.73)$ & 1.04 & $(0.87-1.25)$ & 2 \\
\hline 3 & Cardiac failure & 2.17 & $(1.94-2.43)$ & 1.07 & $(0.95-1.20)$ & 1 \\
\hline 4 & Osteonecrosis of jaw & 2.14 & $(1.83-2.52)$ & 0.60 & $(0.50-0.73)$ & 2 \\
\hline 5 & Gastrointestinal haemorrhage & 2.14 & $(1.89-2.43)$ & 0.77 & $(0.67-0.89)$ & 2 \\
\hline 6 & Pneumonia aspiration & 2.14 & $(1.81-2.52)$ & 1.14 & $(0.96-1.35)$ & 1 \\
\hline 7 & Melaena & 2.08 & $(1.78-2.43)$ & 0.91 & $(0.77-1.07)$ & 2 \\
\hline 8 & Cerebral haemorrhage & 1.88 & $(1.70-2.07)$ & 0.89 & $(0.80-0.99)$ & 2 \\
\hline 9 & Pleural effusion & 1.81 & $(1.54-2.12)$ & 1.00 & $(0.84-1.18)$ & 2 \\
\hline 10 & Cerebral infarction & 1.79 & $(1.62-1.97)$ & 0.73 & $(0.65-0.82)$ & 2 \\
\hline 11 & Delirium & 1.70 & $(1.49-1.94)$ & 1.01 & $(0.87-1.16)$ & 2 \\
\hline 12 & Decreased appetite & 1.55 & $(1.40-1.72)$ & 1.07 & $(0.96-1.20)$ & 1 \\
\hline 13 & Platelet count decreased & 1.46 & $(1.37-1.56)$ & 0.97 & $(0.90-1.04)$ & 2 \\
\hline 14 & Depressed level of consciousness & 1.40 & $(1.21-1.63)$ & 1.06 & $(0.90-1.24)$ & 2 \\
\hline 15 & Pneumonia & 1.40 & $(1.30-1.51)$ & 1.02 & $(0.94-1.11)$ & 1 \\
\hline 16 & Lymphoproliferative disorder & 1.40 & $(1.16-1.68)$ & 0.11 & $(0.06-0.16)$ & 2 \\
\hline 17 & Death & 1.26 & $(1.10-1.43)$ & 0.62 & $(0.53-0.73)$ & 2 \\
\hline 18 & Hypertension & 1.25 & $(1.05-1.50)$ & 0.69 & $(0.56-0.85)$ & 4 \\
\hline 19 & Renal impairment & 1.17 & $(1.08-1.26)$ & 1.02 & $(0.94-1.11)$ & 1 \\
\hline \multicolumn{7}{|c|}{ (b) Female cases } \\
\hline No. & ADEs & $\mathrm{OR}_{\mathrm{e}}$ & $(95 \% \mathrm{CI})$ & $\mathrm{OR}_{\mathrm{p}}$ & $(95 \% \mathrm{CI})$ & Male class \\
\hline 1 & Gastrointestinal haemorrhage & 3.69 & $(3.15-4.33)$ & 1.05 & $(0.90-1.22)$ & 2 \\
\hline 2 & Melaena & 3.22 & $(2.69-3.86)$ & 0.93 & $(0.77-1.11)$ & 2 \\
\hline 3 & Fall & 3.05 & $(2.63-3.54)$ & 0.88 & $(0.75-1.03)$ & 2 \\
\hline 4 & Delirium & 2.89 & $(2.47-3.38)$ & 1.11 & $(0.94-1.29)$ & 2 \\
\hline 5 & Cerebral haemorrhage & 2.61 & $(2.31-2.97)$ & 0.83 & $(0.72-0.95)$ & 2 \\
\hline 6 & Blood creatinine increased & 2.16 & $(1.71-2.73)$ & 1.15 & $(0.90-1.47)$ & 1 \\
\hline 7 & Osteonecrosis of jaw & 2.16 & $(1.95-2.39)$ & 0.71 & $(0.63-0.80)$ & 2 \\
\hline 8 & Death & 1.99 & $(1.69-2.34)$ & 0.67 & $(0.55-0.81)$ & 2 \\
\hline 9 & Cerebral infarction & 1.91 & $(1.71-2.13)$ & 0.63 & $(0.55-0.72)$ & 2 \\
\hline 10 & $\underline{\text { Haemoglobin decreased }}$ & 1.46 & $(1.24-1.72)$ & 0.88 & $(0.73-1.07)$ & 4 \\
\hline 11 & Lymphoproliferative disorder & 1.42 & $(1.26-1.60)$ & 0.10 & $(0.07-0.13)$ & 2 \\
\hline 12 & $\underline{\text { Infection }}$ & 1.26 & $(1.04-1.54)$ & 0.50 & $(0.38-0.64)$ & 4 \\
\hline 13 & Platelet count decreased & 1.23 & $(1.15-1.32)$ & 0.97 & $(0.90-1.06)$ & 2 \\
\hline 14 & Lung disorder & 1.21 & $(1.01-1.45)$ & 1.06 & $(0.87-1.30)$ & 1 \\
\hline 15 & Depressed level of consciousness & 1.21 & $(1.07-1.37)$ & 1.05 & $(0.91-1.20)$ & 2 \\
\hline 16 & Pleural effusion & 1.20 & $(1.02-1.43)$ & 1.12 & $(0.93-1.35)$ & 2 \\
\hline 17 & $\underline{\text { Shock }}$ & 1.20 & $(1.09-1.32)$ & 0.89 & $(0.80-1.00)$ & 4 \\
\hline 18 & Dizziness & 1.20 & $(1.06-1.35)$ & 0.94 & $(0.82-1.07)$ & 1 \\
\hline 19 & $\underline{\text { Stomatitis }}$ & 1.19 & $(1.02-1.38)$ & 1.01 & $(0.85-1.19)$ & 4 \\
\hline
\end{tabular}

Underlined ADEs are categorised in a separate Class in the other sex

$O R_{e}$ adjusted odds ratio with elderly as a factor for the occurrence of ADEs, $O R_{p}$ adjusted odds ratio with polypharmacy as a factor for the occurrence of ADEs, 95\% CI 95\% confidence interval of $\mathrm{OR}_{\mathrm{e}}$ and $\mathrm{OR}_{\mathrm{p}}$. Female Class class in which ADEs common in females are categorised, Male Class class in which ADEs common in males are categorised 
appetite, rhabdomyolysis, cardiac failure, pneumonia) were significant for females only.

\subsection{ADEs That are Associated with Elderly and Not With Polypharmacy: Class 2 [E(+), P(-)]}

ADEs categorised as Class 2 are presented by sex in Table 3 ((a) Males, (b) Females). The ADEs in Table 3 were ranked in descending $\mathrm{OR}_{\mathrm{e}}$ order A total of 19 male and female ADE types, respectively, were categorised as Class 2. Of these, 12 were categorised as being common to both males and females. $\mathrm{OR}_{\mathrm{e}}$ for males presented high values for urinary retention (OR 3.34), fall (OR 2.29), cardiac failure (OR 2.17), osteonecrosis of the jaw (OR 2.14), and gastrointestinal haemorrhage (OR 2.14). For females, high values were found for gastrointestinal haemorrhage (OR 3.69), melaena (OR 3.22), fall (OR 3.05), delirium (OR 2.89), and cerebral haemorrhage (OR 2.61). Except for mental and nervous disorders, various ADEs were categorised in Class 2. Hypertension was common to males, while decreased haemoglobin, infection, shock and stomatitis were common to females.

\subsection{ADEs That are Associated with Polypharmacy and Not With Elderly: Class 3 [E(-), P(+)]}

Class 3 ADEs are presented by sex in Table 4 ((a) Males, (b) Females). ADEs in Table 4 and $\mathrm{OR}_{\mathrm{p}}$ are ranked in descending order. In total, 14 and $20 \mathrm{ADE}$ types common to both males and females, respectively, were categorised as Class 3. Of these, nine were common to both males and females.

$\mathrm{OR}_{\mathrm{p}}$ for males included drug interaction (OR 2.16), agranulocytosis (OR 1.62), rhabdomyolysis (OR 1.60), erythema (OR 1.41), and toxic skin eruption (OR 1.31). For females, the ranking was sepsis (OR 1.60), cellulitis (OR 1.48), hyperglycaemia (OR 1.47), neuroleptic malignant syndrome (OR 1.45), and erythema (OR 1.39).

In Class 3, the PTs infectious diseases and decreased white blood cell count predominated. Septic shock and decreased white blood cell count were categorised as common to males, while sepsis, cellulitis, hyperglycaemia, acute pancreatitis, increased blood creatine phosphokinase, Stevens-Johnson syndrome, jaundice, increased aspartate aminotransferase, toxic epidermal necrolysis, vomiting, and drug-induced liver injury were categorised as common to females.

\subsection{ADEs That are Not Associated with Either Polypharmacy or Elderly: Class 4 [E(-), P(-)]}

Class 4 ADEs are presented by sex in Table 5 ((a) Males, (b) Females). $\mathrm{OR}_{\mathrm{e}}$ and $\mathrm{OR}_{\mathrm{p}}$ volumes are ranked in ascending order to clarify that ADEs were unaffected by elderly or polypharmacy. A total of 48 and $35 \mathrm{ADE}$ types were categorised as male and female, respectively. Of these, 32 were common to both sexes. Class 4 ADEs were dominated by allergic symptoms, including anaphylactic reaction.

\subsection{Summary of the Results}

ADE classes are presented in Fig. 3.

\section{Discussion}

Class 2 ADEs $[\mathrm{E}(+), \mathrm{P}(-)]$, including the PTs delirium and fall, have previously been identified as those with a high risk of occurrence in elderly patients treated with polypharmacy [10]. However, these ADEs were associated with the elderly but not with polypharmacy in this study. Moreover, it is difficult to distinguish between symptoms associated with drugs and those associated with aging, and symptoms may actually include symptoms of aging.

Conversely, the results of the present study support existing reports that the risk of Class $1 \mathrm{ADEs}[\mathrm{E}(+), \mathrm{P}(+)]$, including electrolyte abnormalities [15-17], renal disorder [3] and pneumonia aspiration [18, 19], in elderly patients treated with polypharmacy is high. Dehydration and electrolyte imbalance are common in elderly persons, who have a high threshold value for throat dryness; moreover, polypharmacy including diuretics and selective serotonin receptor inhibitors has been reported [15-17] to increase these risks. In addition to the reduction in renal function associated with the elderly [3], multi-drug combinations of non-steroidal anti-inflammatory drugs, hypotensive drugs and diuretics have been reported to increase the risk of renal disorders. Similarly, reduced mobility in the elderly leads to decreased swallowing function, and multi-drug combinations including those with muscle-relaxing properties and diuretics carry a risk of pneumonia aspiration $[18,19]$.

The PTs decreased white blood cell count and infectious diseases predominate among the Class 3 ADEs [E(-), $\mathrm{P}(+)$ ] that are common to both sexes. This indicates that there is an age-independent risk of myelosuppression with combinations of anti-cancer agents, which subsequently increase the risk of infections. In addition, given that many Class 4 ADEs $[\mathrm{E}(-), \mathrm{P}(-)]$ were found to be allergic in nature, the high risk of allergy-type ADEs unrelated to polypharmacy or elderly should be considered.

In this study, sex differences in the occurrence of ADEs were investigated. ADEs of which the risk of onset is associated with polypharmacy occurred more frequently in women (Tables 2,3), which may suggest that women 
Table 4 Adverse drug events (ADEs) categorised as Class 3 (in $\mathrm{OR}_{\mathrm{p}}$ descending order)

\begin{tabular}{|c|c|c|c|c|c|c|}
\hline No. & ADEs & $\mathrm{OR}_{\mathrm{e}}$ & $(95 \% \mathrm{CI})$ & $\mathrm{OR}_{\mathrm{p}}$ & $(95 \% \mathrm{CI})$ & Female class \\
\hline 1 & Drug interaction & 1.05 & $(0.91-1.21)$ & 2.16 & $(1.87-2.49)$ & 1 \\
\hline 2 & Agranulocytosis & 0.69 & $(0.60-0.79)$ & 1.62 & $(1.42-1.84)$ & 3 \\
\hline 3 & Rhabdomyolysis & 0.86 & $(0.80-0.93)$ & 1.60 & $(1.48-1.73)$ & 1 \\
\hline 4 & Erythema & 0.91 & $(0.78-1.06)$ & 1.41 & $(1.20-1.66)$ & 3 \\
\hline 5 & Toxic skin eruption & 0.69 & $(0.57-0.84)$ & 1.31 & $(1.07-1.60)$ & 3 \\
\hline 6 & $\underline{\text { Septic shock }}$ & 0.80 & $(0.66-0.97)$ & 1.28 & $(1.05-1.55)$ & 4 \\
\hline 7 & Electrocardiogram qt prolonged & 1.17 & $(0.98-1.39)$ & 1.25 & $(1.04-1.49)$ & 1 \\
\hline 8 & Anaphylactic shock & 0.70 & $(0.67-0.74)$ & 1.22 & $(1.15-1.28)$ & 3 \\
\hline 9 & Neuroleptic malignant syndrome & 0.31 & $(0.26-0.35)$ & 1.19 & $(1.05-1.34)$ & 3 \\
\hline 10 & Hepatic function abnormal & 0.88 & $(0.83-0.93)$ & 1.17 & $(1.11-1.25)$ & 3 \\
\hline 11 & Drug eruption & 0.71 & $(0.65-0.78)$ & 1.16 & $(1.05-1.27)$ & 3 \\
\hline 12 & Disseminated intravascular coagulation & 1.11 & $(0.98-1.25)$ & 1.16 & $(1.01-1.32)$ & 3 \\
\hline 13 & Pyrexia & 0.87 & $(0.82-0.94)$ & 1.13 & $(1.05-1.22)$ & 3 \\
\hline 14 & White blood cell count decreased & 0.88 & $(0.80-0.97)$ & 1.11 & $(1.01-1.23)$ & 4 \\
\hline \multicolumn{7}{|c|}{ (b) Female cases } \\
\hline No. & ADEs & $\mathrm{OR}_{\mathrm{e}}$ & $(95 \% \mathrm{CI})$ & $\mathrm{OR}_{\mathrm{p}}$ & $(95 \% \mathrm{CI})$ & Male class \\
\hline 1 & $\underline{\text { Sepsis }}$ & 0.91 & $(0.79-1.05)$ & 1.60 & $(1.38-1.84)$ & 4 \\
\hline 2 & Cellulitis & 1.13 & $(0.93-1.38)$ & 1.48 & $(1.20-1.81)$ & 4 \\
\hline 3 & Hyperglycaemia & 0.90 & $(0.75-1.08)$ & 1.47 & $(1.22-1.77)$ & 4 \\
\hline 4 & Neuroleptic malignant syndrome & 0.49 & $(0.42-0.57)$ & 1.45 & $(1.26-1.67)$ & 3 \\
\hline 5 & Erythema & 0.62 & $(0.54-0.72)$ & 1.39 & $(1.20-1.59)$ & 3 \\
\hline 6 & $\underline{\text { Pancreatitis acute }}$ & 0.65 & $(0.54-0.78)$ & 1.38 & $(1.14-1.66)$ & 4 \\
\hline 7 & Disseminated intravascular coagulation & 1.06 & $(0.92-1.22)$ & 1.38 & $(1.19-1.59)$ & 3 \\
\hline 8 & Blood creatine phosphokinase increased & 0.92 & $(0.79-1.07)$ & 1.34 & $(1.14-1.57)$ & 4 \\
\hline 9 & Toxic skin eruption & 0.75 & $(0.63-0.89)$ & 1.31 & $(1.09-1.56)$ & 3 \\
\hline 10 & $\underline{\text { Stevens-Johnson syndrome }}$ & 0.70 & $(0.63-0.77)$ & 1.29 & $(1.16-1.42)$ & 4 \\
\hline 11 & $\underline{\text { Jaundice }}$ & 1.04 & $(0.88-1.24)$ & 1.26 & $(1.05-1.51)$ & 4 \\
\hline 12 & $\underline{\text { Aspartate aminotransferase increased }}$ & 0.87 & $(0.74-1.03)$ & 1.24 & $(1.04-1.47)$ & 4 \\
\hline 13 & $\underline{\text { Toxic epidermal necrolysis }}$ & 0.81 & $(0.70-0.93)$ & 1.23 & $(1.06-1.42)$ & 4 \\
\hline 14 & Anaphylactic shock & 0.68 & $(0.64-0.72)$ & 1.19 & $(1.12-1.27)$ & 3 \\
\hline 15 & Vomiting & 1.11 & $(1.00-1.22)$ & 1.18 & $(1.05-1.31)$ & 4 \\
\hline 16 & Drug-induced liver injury & 0.57 & $(0.50-0.65)$ & 1.15 & $(1.01-1.31)$ & 4 \\
\hline 17 & Pyrexia & 0.74 & $(0.69-0.80)$ & 1.14 & $(1.06-1.23)$ & 3 \\
\hline 18 & Agranulocytosis & 0.62 & $(0.55-0.69)$ & 1.13 & $(1.01-1.26)$ & 3 \\
\hline 19 & Drug eruption & 0.61 & $(0.56-0.67)$ & 1.12 & $(1.03-1.22)$ & 3 \\
\hline 20 & Hepatic function abnormal & 0.79 & $(0.75-0.84)$ & 1.09 & $(1.02-1.16)$ & 3 \\
\hline
\end{tabular}

Underlined ADEs are categorised in a separate Class in the other sex

$O R_{e}$ adjusted odds ratio with elderly as a factor for the occurrence of ADEs, $O R_{p}$ adjusted odds ratio with polypharmacy as a factor for the occurrence of ADEs, 95\% CI 95\% confidence interval of $\mathrm{OR}_{\mathrm{e}}$ and $\mathrm{OR}_{\mathrm{p}}$. Female Class class in which ADEs common in females are categorised, Male Class class in which ADEs common in males are categorised

are more sensitive to the effects of polypharmacy than are men [20, 21]. However, the type of drug used was not included in the analysis conditions. Thus, detailed investigations focusing on the types of drugs used are necessary for a detailed discussion on the reasons for these sex differences.
This study has the following limitations: since this study focused on the 100 most common ADE types reported in the JADER database, it is possible that ADEs categorised as Class 1 were not the only events that carry a high risk of occurrence in elderly patients treated with polypharmacy: other ADEs may carry a high risk of occurrence in 
Table 5 Adverse drug events (ADEs) categorised as Class $4\left(\mathrm{OR}_{\mathrm{e}}\right.$ and $\mathrm{OR}_{\mathrm{p}}$ volumes in ascending order)

\begin{tabular}{|c|c|c|c|c|c|c|}
\hline No. & ADEs & $\mathrm{OR}_{\mathrm{e}}$ & $(95 \% \mathrm{CI})$ & $\mathrm{OR}_{\mathrm{p}}$ & $(95 \% \mathrm{CI})$ & Female class \\
\hline 1 & Cytomegalovirus infection & 0.33 & $(0.26-0.41)$ & 0.74 & $(0.60-0.92)$ & 4 \\
\hline 2 & Drug reaction with eosinophilia and systemic symptoms & 0.37 & $(0.33-0.42)$ & 0.77 & $(0.68-0.88)$ & 4 \\
\hline 3 & Diabetes mellitus & 0.49 & $(0.41-0.59)$ & 0.65 & $(0.53-0.79)$ & 4 \\
\hline 4 & Headache & 0.44 & $(0.33-0.56)$ & 0.85 & $(0.65-1.09)$ & 4 \\
\hline 5 & Tubulointerstitial nephritis & 0.53 & $(0.44-0.63)$ & 0.74 & $(0.61-0.88)$ & 4 \\
\hline 6 & Palmar-plantar erythrodysaesthesia syndrome & 0.95 & $(0.75-1.19)$ & 0.44 & $(0.31-0.59)$ & 4 \\
\hline 7 & Anaphylactoid reaction & 0.43 & $(0.37-0.51)$ & 1.15 & $(0.99-1.34)$ & 4 \\
\hline 8 & Anaphylactic reaction & 0.51 & $(0.46-0.56)$ & 1.02 & $(0.92-1.13)$ & 4 \\
\hline 9 & Pancreatitis acute & 0.50 & $(0.42-0.59)$ & 1.04 & $(0.88-1.22)$ & 3 \\
\hline 10 & Peritonitis & 0.69 & $(0.57-0.84)$ & 0.79 & $(0.63-0.97)$ & 4 \\
\hline 11 & Urticaria & 0.52 & $(0.45-0.60)$ & 1.09 & $(0.94-1.26)$ & 4 \\
\hline 12 & Neutrophil count decreased & 0.92 & $(0.84-1.01)$ & 0.65 & $(0.58-0.73)$ & 4 \\
\hline 13 & Infection & 0.99 & $(0.82-1.19)$ & 0.61 & $(0.48-0.76)$ & 2 \\
\hline 14 & Drug-induced liver injury & 0.74 & $(0.65-0.84)$ & 0.84 & $(0.72-0.96)$ & 3 \\
\hline 15 & Pulmonary embolism & 0.58 & $(0.47-0.72)$ & 1.11 & $(0.89-1.37)$ & 4 \\
\hline 16 & Pneumocystis jirovecii pneumonia & 0.90 & $(0.78-1.04)$ & 0.72 & $(0.61-0.85)$ & 4 \\
\hline 17 & Stevens-Johnson syndrome & 0.62 & $(0.56-0.69)$ & 1.06 & $(0.95-1.18)$ & 3 \\
\hline 18 & Deep vein thrombosis & 0.70 & $(0.56-0.86)$ & 0.95 & $(0.75-1.18)$ & 4 \\
\hline 19 & Rash generalised & 0.78 & $(0.66-0.92)$ & 0.85 & $(0.71-1.02)$ & 4 \\
\hline 20 & Erythema multiforme & 0.73 & $(0.64-0.83)$ & 0.92 & $(0.80-1.05)$ & 4 \\
\hline 21 & Alanine aminotransferase increased & 0.75 & $(0.64-0.87)$ & 0.90 & $(0.76-1.06)$ & 4 \\
\hline 22 & Bone marrow failure & 0.99 & $(0.88-1.11)$ & 0.68 & $(0.59-0.79)$ & 4 \\
\hline 23 & Neutropenia & 0.84 & $(0.75-0.92)$ & 0.81 & $(0.72-0.91)$ & 4 \\
\hline 24 & Rash & 0.67 & $(0.60-0.74)$ & 1.02 & $(0.92-1.14)$ & 4 \\
\hline 25 & Leukopenia & 0.85 & $(0.73-0.98)$ & 0.82 & $(0.70-0.97)$ & 4 \\
\hline 26 & Blood creatine phosphokinase increased & 0.66 & $(0.59-0.74)$ & 1.06 & $(0.94-1.20)$ & 3 \\
\hline 27 & Stomatitis & 0.88 & $(0.75-1.03)$ & 0.80 & $(0.66-0.96)$ & 2 \\
\hline 28 & Toxicity to various agents & 0.64 & $(0.54-0.76)$ & 1.15 & $(0.96-1.37)$ & 4 \\
\hline 29 & Seizure & 0.77 & $(0.69-0.85)$ & 0.98 & $(0.87-1.09)$ & 4 \\
\hline 30 & Liver disorder & 0.78 & $(0.72-0.84)$ & 1.04 & $(0.96-1.12)$ & 4 \\
\hline 31 & Hyperglycaemia & 0.84 & $(0.71-0.99)$ & 0.97 & $(0.80-1.16)$ & 3 \\
\hline 32 & Shock & 0.97 & $(0.89-1.06)$ & 0.87 & $(0.78-0.96)$ & 2 \\
\hline 33 & Toxic epidermal necrolysis & 0.73 & $(0.63-0.84)$ & 1.16 & $(1.00-1.35)$ & 3 \\
\hline 34 & Aspartate aminotransferase increased & 0.83 & $(0.71-0.96)$ & 1.02 & $(0.86-1.21)$ & 3 \\
\hline 35 & Nausea & 0.87 & $(0.76-0.98)$ & 1.00 & $(0.87-1.14)$ & 4 \\
\hline 36 & Diarrhoea & 0.97 & $(0.88-1.07)$ & 0.94 & $(0.84-1.04)$ & 4 \\
\hline 37 & Herpes zoster & 0.81 & $(0.63-1.04)$ & 1.13 & $(0.87-1.47)$ & 4 \\
\hline 38 & Febrile neutropenia & 1.04 & $(0.93-1.15)$ & 0.89 & $(0.79-1.00)$ & 4 \\
\hline 39 & Sepsis & 0.86 & $(0.76-0.98)$ & 1.08 & $(0.94-1.23)$ & 3 \\
\hline 40 & Malaise & 1.02 & $(0.89-1.16)$ & 0.93 & $(0.80-1.08)$ & 4 \\
\hline 41 & Loss of consciousness & 1.10 & $(0.99-1.22)$ & 0.90 & $(0.80-1.01)$ & 4 \\
\hline 42 & Haemoglobin decreased & 1.17 & $(1.00-1.38)$ & 0.84 & $(0.70-1.01)$ & 2 \\
\hline 43 & Ileus & 1.05 & $(0.88-1.25)$ & 0.96 & $(0.79-1.16)$ & 4 \\
\hline 44 & Renal disorder & 1.05 & $(0.92-1.20)$ & 0.97 & $(0.83-1.12)$ & 1 \\
\hline 45 & Jaundice & 1.05 & $(0.90-1.22)$ & 0.97 & $(0.82-1.14)$ & 3 \\
\hline 46 & Cellulitis & 0.90 & $(0.71-1.14)$ & 1.14 & $(0.89-1.46)$ & 3 \\
\hline 47 & Vomiting & 1.00 & $(0.88-1.14)$ & 1.13 & $(0.98-1.29)$ & 3 \\
\hline 48 & Dyspnoea & 1.05 & $(0.94-1.16)$ & 1.11 & $(0.99-1.23)$ & 4 \\
\hline
\end{tabular}


Table 5 (continued)

\begin{tabular}{|c|c|c|c|c|c|c|}
\hline \multicolumn{7}{|c|}{ (a) Female cases } \\
\hline No. & ADEs & $\mathrm{OR}_{\mathrm{e}}$ & $(95 \% \mathrm{CI})$ & $\mathrm{OR}_{\mathrm{p}}$ & $(95 \% \mathrm{CI})$ & Male class \\
\hline 1 & Headache & 0.31 & $(0.25-0.37)$ & 0.59 & $(0.49-0.71)$ & 4 \\
\hline 2 & Anaphylactoid reaction & 0.36 & $(0.30-0.42)$ & 1.03 & $(0.88-1.21)$ & 4 \\
\hline 3 & Cytomegalovirus infection & 0.46 & $(0.36-0.57)$ & 0.84 & $(0.66-1.06)$ & 4 \\
\hline 4 & Anaphylactic reaction & 0.39 & $(0.35-0.43)$ & 1.00 & $(0.90-1.10)$ & 4 \\
\hline 5 & Palmar-plantar erythrodysaesthesia syndrome & 0.79 & $(0.61-1.02)$ & 0.51 & $(0.36-0.71)$ & 4 \\
\hline 6 & Pulmonary embolism & 0.55 & $(0.47-0.64)$ & 0.81 & $(0.69-0.95)$ & 4 \\
\hline 7 & Drug reaction with eosinophilia and systemic symptoms & 0.47 & $(0.41-0.53)$ & 0.98 & $(0.86-1.11)$ & 4 \\
\hline 8 & Neutrophil count decreased & 0.73 & $(0.65-0.81)$ & 0.64 & $(0.56-0.73)$ & 4 \\
\hline 9 & Neutropenia & 0.61 & $(0.54-0.68)$ & 0.82 & $(0.73-0.93)$ & 4 \\
\hline 10 & Deep vein thrombosis & 0.70 & $(0.61-0.81)$ & 0.72 & $(0.61-0.85)$ & 4 \\
\hline 11 & Urticaria & 0.49 & $(0.42-0.56)$ & 1.07 & $(0.93-1.23)$ & 4 \\
\hline 12 & Febrile neutropenia & 0.61 & $(0.53-0.70)$ & 0.87 & $(0.75-1.00)$ & 4 \\
\hline 13 & Diabetes mellitus & 0.54 & $(0.44-0.66)$ & 1.00 & $(0.82-1.23)$ & 4 \\
\hline 14 & Tubulointerstitial nephritis & 0.65 & $(0.54-0.78)$ & 0.85 & $(0.69-1.05)$ & 4 \\
\hline 15 & Rash & 0.56 & $(0.51-0.61)$ & 1.05 & $(0.96-1.16)$ & 4 \\
\hline 16 & Erythema multiforme & 0.71 & $(0.64-0.80)$ & 0.84 & $(0.74-0.94)$ & 4 \\
\hline 17 & Seizure & 0.71 & $(0.65-0.79)$ & 0.84 & $(0.75-0.95)$ & 4 \\
\hline 18 & Malaise & 0.70 & $(0.61-0.79)$ & 0.94 & $(0.81-1.08)$ & 4 \\
\hline 19 & Peritonitis & 0.79 & $(0.65-0.96)$ & 0.84 & $(0.66-1.04)$ & 4 \\
\hline 20 & Hypertension & 0.88 & $(0.73-1.06)$ & 0.76 & $(0.60-0.94)$ & 2 \\
\hline 21 & Bone marrow failure & 1.07 & $(0.95-1.21)$ & 0.66 & $(0.56-0.76)$ & 4 \\
\hline 22 & Leukopenia & 0.71 & $(0.61-0.82)$ & 1.00 & $(0.85-1.17)$ & 4 \\
\hline 23 & Liver disorder & 0.73 & $(0.68-0.79)$ & 0.97 & $(0.90-1.06)$ & 4 \\
\hline 24 & Toxicity to various agents & 0.69 & $(0.59-0.80)$ & 1.05 & $(0.89-1.23)$ & 4 \\
\hline 25 & Dyspnoea & 0.78 & $(0.70-0.86)$ & 1.00 & $(0.89-1.12)$ & 4 \\
\hline 26 & Rash generalised & 0.82 & $(0.72-0.95)$ & 1.05 & $(0.90-1.22)$ & 4 \\
\hline 27 & Nausea & 0.89 & $(0.80-0.99)$ & 0.98 & $(0.88-1.10)$ & 4 \\
\hline 28 & Herpes zoster & 0.85 & $(0.70-1.02)$ & 1.06 & $(0.86-1.30)$ & 4 \\
\hline 29 & Alanine aminotransferase increased & 0.81 & $(0.69-0.95)$ & 1.12 & $(0.94-1.32)$ & 4 \\
\hline 30 & White blood cell count decreased & 0.87 & $(0.80-0.95)$ & 1.05 & $(0.95-1.16)$ & 3 \\
\hline 31 & Loss of consciousness & 0.99 & $(0.90-1.09)$ & 0.93 & $(0.83-1.03)$ & 4 \\
\hline 32 & Diarrhoea & 0.92 & $(0.83-1.01)$ & 1.04 & $(0.93-1.16)$ & 4 \\
\hline 33 & Ileus & 1.16 & $(0.95-1.42)$ & 0.86 & $(0.68-1.07)$ & 4 \\
\hline 34 & Septic shock & 0.86 & $(0.71-1.05)$ & 1.22 & $(0.99-1.49)$ & 3 \\
\hline 35 & Pneumocystis jirovecii pneumonia & 1.07 & $(0.95-1.20)$ & 1.04 & $(0.91-1.18)$ & 4 \\
\hline
\end{tabular}

$O R_{e}$ adjusted odds ratio with elderly as a factor for the occurrence of ADEs, $O R_{p}$ adjusted odds ratio with polypharmacy as a factor for the occurrence of ADEs, 95\% CI 95\% confidence interval of $\mathrm{OR}_{\mathrm{e}}$ and $\mathrm{OR}_{\mathrm{p}}$ Female Class class in which ADEs common in females are categorised, Male Class class in which ADEs common in males are categorised

polypharmacy-treated patients. In addition, because ADEs were categorised using only basic data (age, sex and number of concomitant drugs) in the JADER, questions as to whether Class 1-categorised ADEs were really caused by polypharmacy, or whether other factors (e.g. background diseases or individual drugs) were involved highlight the need for studies from both pharmacological and physiological perspectives.
In conclusion, analysis of ADEs considering polypharmacy and the elderly revealed that the risk of the 100 most common ADEs reported in the JADER database could be categorised as follows: electrolyte abnormalities, renal and respiratory disorders, and coagulopathy in Class $1[\mathrm{E}(+)$, $\mathrm{P}(+)]$; delirium, falls in Class $2[\mathrm{E}(+), \mathrm{P}(-)]$; myelosuppression arising from anti-cancer multi-drug combinations in Class $3[\mathrm{E}(-), \mathrm{P}(+)]$; and allergy-type ADEs in Class 
Fig. 3 Typical adverse drug events (ADEs) categorised into each class. $O R_{e}$ adjusted odds ratio with elderly as a factor for the occurrence of ADEs, $O R_{p}$ adjusted odds ratio with polypharmacy as a factor for the occurrence of ADEs. E(+), $\mathrm{P}(+)$ : ADEs where $\mathrm{OR}_{\mathrm{e}}$ and $\mathrm{OR}_{\mathrm{p}}$ significantly exceeded 1 ; $\mathrm{E}(+), \mathrm{P}(-)$ : ADEs where only $\mathrm{OR}_{\mathrm{e}}$ significantly exceeded 1 ; $\mathrm{E}(-), \mathrm{P}(+)$ : ADEs where only $\mathrm{OR}_{\mathrm{p}}$ significantly exceeded 1 ; $\mathrm{E}(-), \mathrm{P}(-)$ : ADEs where neither $\mathrm{OR}_{\mathrm{e}}$ nor $\mathrm{OR}_{\mathrm{p}}$ significantly exceeded 1

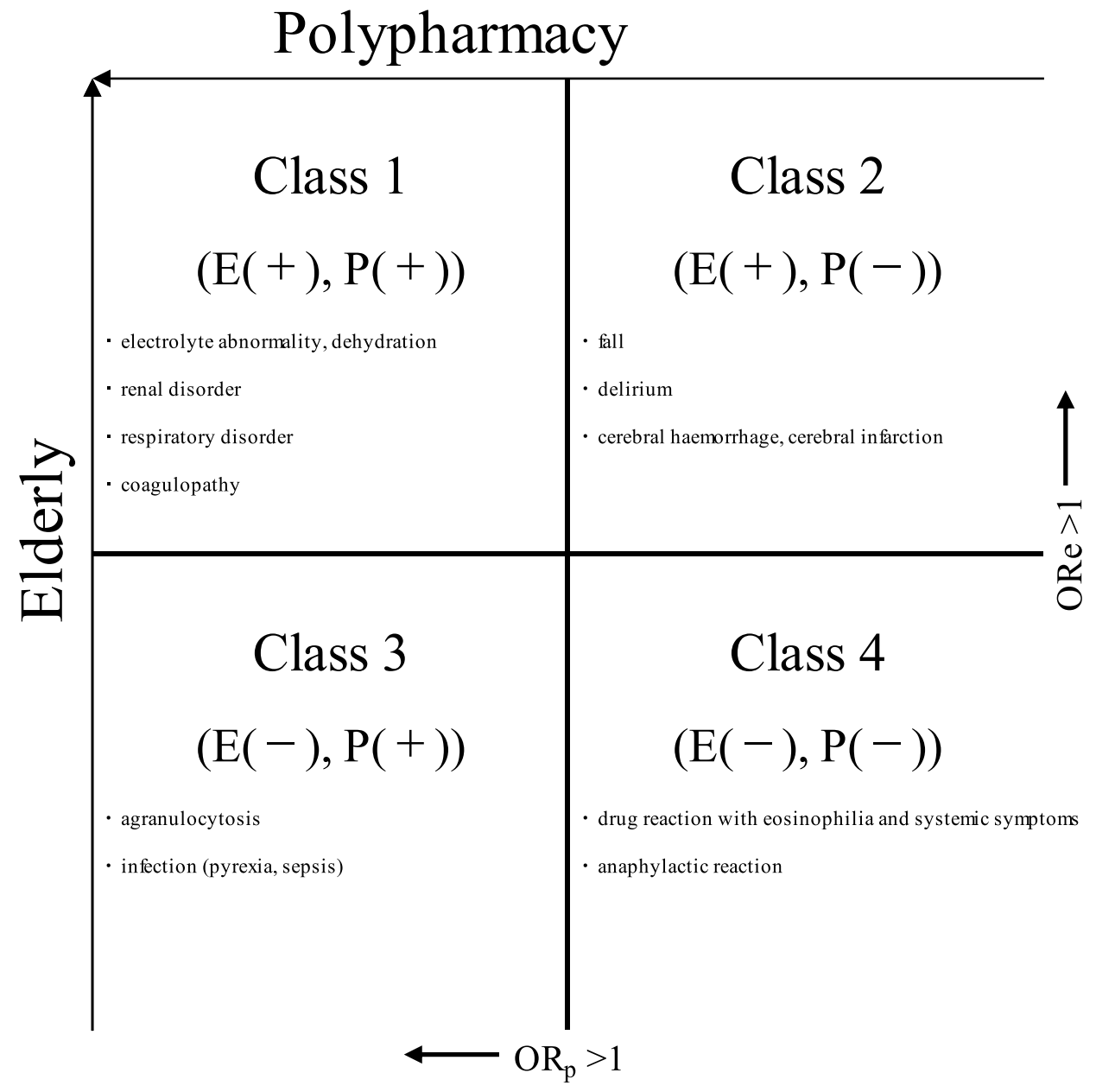

Data availability The datasets supporting the conclusions of this article are available in the Pharmaceuticals and Medical Devices Agency repository, https://www.pmda.go.jp/.

Ethics approval Not applicable.

Consent Not applicable.

Author contributions AN, NI and DK contributed to the conception and initial design of the manuscript. AN was the major contributor to the design and writing of the manuscript. MM and DK contributed to the final design and writing of the manuscript. SO contributed to the project administration. AN and $\mathrm{NH}$ contributed to the data curation, methodology, software and formal analysis. SN and SOh contributed to the review and editing. DK contributed to the conceptualization. All authors read and approved the final manuscript.

Open Access This article is licensed under a Creative Commons Attribution-NonCommercial 4.0 International License, which permits any non-commercial use, sharing, adaptation, distribution and reproduction in any medium or format, as long as you give appropriate credit to the original author(s) and the source, provide a link to the Creative Commons licence, and indicate if changes were made. The images or other third party material in this article are included in the article's Creative Commons licence, unless indicated otherwise in a credit line to the material. If material is not included in the article's Creative Commons licence and your intended use is not permitted by statutory

interest. 
regulation or exceeds the permitted use, you will need to obtain permission directly from the copyright holder. To view a copy of this licence, visit http://creativecommons.org/licenses/by-nc/4.0/.

\section{References}

1. Sönnerstam E, Sjölander M, Lövheim H, Gustafsson M. Clinically relevant drug-drug interactions among elderly people with dementia. Eur J Clin Pharmacol. 2018;74:1351-60.

2. Kim HA, Shin JY, Kim MH, Park BJ. Prevalence and predictors of polypharmacy among Korean elderly. PLoS ONE. 2014;9:e98043.

3. Abe J, Umetsu R, Uranishi H, Suzuki H, Nishibata Y, Kato Y, Ueda N, Sasaoka S, Hatahira H, Motooka Y, Masuta M, Nakamura M. Analysis of polypharmacy effects in older patients using Japanese Adverse Drug Event Report database. PLoS ONE. 2017;12:e190102.

4. Mortazavi SS, Shati M, Keshtkar A, Malakouti SK, Bazargan M, Assari S. Defining polypharmacy in the elderly: a systematic review protocol. BMJ Open. 2016;6:e010989.

5. Best O, Gnjidic D, Hilmer SN, Naganathan V, McLachlan AJ. Investigating polypharmacy and drug burden index in hospitalised older people. Intern Med J. 2013;43:912-8.

6. Pfister B, Jonsson J, Gustafsson M. Drug-related problems and medication reviews among old people with dementia. BMC Pharmacol Toxicol. 2017;18:52.

7. Leiss W, Méan M, Limacher A, Righini M, Jaeger K, Beer HJ, Osterwalder J, Frauchiger B, Matter CM, Kucher N, AngelilloScherrer A, Cornuz J, Banyai M, Lämmle B, Husmann M, Egloff M, Aschwanden M, Rodondi N, Aujesky D. Polypharmacy is associated with an increased risk of bleeding in elderly patients with venous thromboembolism. J Gen Intern Med. 2015;30:17-24.

8. Masnoon N, Shakib S, Kalisch-Ellett L, Caughey GE. What is polypharmacy? A systematic review of definitions. BMC Geriatr. 2017; 17:230

9. Stevenson JM, Davies JG, Martin FC. Medication-related harm: a geriatric syndrome. Age Aging. 2019. https://doi.org/10.1093/ ageing/afz121.

10. Davies EA, O’Mahony MS. Adverse drug reactions in special populations - the elderly. Br J Clin Pharmacol. 2015;80:796-807.
11. Kuzuya M, Masuda Y, Hirakawa Y, Iwata M, Enoki H, Hasegawa $\mathrm{J}$, Cheng XW, Iguchi A. Underuse of medications for chronic diseases in the oldest of community-dwelling older frail Japanese. J Am Geriatr Soc. 2006;54:598-605.

12. Kojima T, Akishita M, Kameyama Y, Yamaguchi K, Yamamoto $\mathrm{H}$, Eto M, Ouchi Y. High risk of adverse drug reactions in elderly patients taking six or more drugs: analysis of inpatient database. Geriatr Gerontol Int. 2012;12:761-2.

13. Chisaki Y, Aoji S, Yano Y. Analysis of adverse drug reaction risk in elderly patients using the Japanese Adverse Drug Event Report (JADER) database. Biol Pharm Bull. 2017;40:824-9.

14. Ueda N, Umetsu R, Abe J, Kato Y, Nakayama Y, Kato Z, Kinosada Y, Nakamura M. Analysis of neuropsychiatric adverse events in patients treated with oseltamivir in spontaneous adverse event reports. Biol Pharm Bull. 2015;38:1638-44.

15. Mack GW, Weseman CA, Langhans GW, Scherzer H, Gillen CM, Nadel ER. Body fluid balance in dehydrated healthy older men: thirst and renal osmoregulation. J Appl Physiol. 1985; 1994(76):1615-23.

16. Koch CA, Fulop T. Clinical aspects of changes in water and sodium homeostasis in the elderly. Rev Endocr Metab Disord. 2017;18:49-66.

17. Miller M, Moses AM. Drug-induced stated of impaired water excretion. Kidney Int. 1976;10:96-103.

18. Wirth R, Dziewas R, Beck AM, Clavé P, Hamdy S, Heppner HJ, Langmore S, Leischker AH, Martino R, Pluschinski P, Rösler A, Shaker R, Warnecke T, Sieber CC, Volkert D. Oropharyngeal dysphagia in older persons-from pathophysiology to adequate intervention: a review and summary of an international expert meeting. Clin Interv Aging. 2016;11:189-208.

19. Tagliaferri S, Lauretani F, Pelá G, Meschi T, Maggio M. The risk of dysphagia is associated with malnutrition and poor functional outcomes in a large population of outpatient older individuals. Clin Nutr. 2018;38:2684-9.

20. Pereira KG, Peres MA, Iop D, Boing AC, Boing AF, Aziz M, d'Orsi E. Polypharmacy among the elderly: a population-based study. Rev Bras Epidemiol. 2017;20:335-44.

21. Marković-Peković V, Škrbić R, Petrović A, Vlahović-Palčevski V, Mrak J, Bennie M, Fadare J, Kwon HY, Schiffers K, Truter I, Godman B. Polypharmacy among the elderly in the Republic of Srpska: extent and implications for the future. Expert Rev Pharmacoecon Outcomes Res. 2016;16:609-18. 